\title{
PROPAGAÇÃO DA CORTICEIRA DO BANHADO (Erythrina crista-galli L.) (FABACEAE) PELO PROCESSO DE ESTAQUIA ${ }^{1}$
}

\author{
Ariane Gratieri-Sossella², Cláudia Petry ${ }^{3}$ e Alexandre Augusto Nienow ${ }^{2}$
}

\begin{abstract}
RESUMO - A corticeira-do-banhado é uma árvore nativa com uso ornamental no paisagismo urbano e possui potencial de utilização em áreas desprotegidas e degradadas, devido a sua rusticidade. Entretanto, tendo em vista a dificuldade de obtenção de sementes, pela baixa produção e qualidade destas com a conseqüente desuniformidade da germinação, torna-se necessário aprofundar o estudo de outras formas de propagação dessa espécie. Desse modo, conduziu-se este trabalho na Faculdade de Agronomia e Medicina Veterinária da Universidade de Passo Fundo, com o objetivo de estudar a formação de mudas de Erythrina crista-galli L. pela técnica da estaquia. Em quatro experimentos foram testadas doses do fitorregulador ácido indolbutírico (AIB), em diferentes tipos de estacas (lenhosas, semilenhosas, herbáceas e foliares) e substratos. Os resultados indicaram que mini-estacas herbáceas, coletadas de plantas jovens, com menos de 1 ano de idade, são as mais indicadas (75\% a 100\% de enraizamento), e o uso do AIB diminuiu a mortalidade, ao favorecer o processo do enraizamento. Em razão do ataque de insetos (brocas) às plantas no seu hábitat, recomenda-se a técnica de jardim clonal, com a formação de matrizeiros no viveiro, fornecendo material juvenil e sadio em maior escala para a propagação dessa espécie por miniestacas.
\end{abstract}

Palavras-chave: Propagação vegetativa, estacas e juvenilidade.

\section{PROPAGATION OF SWAMP CORTICEIRA (Erythrina crista-galli L.) (FABACEAE) BY THE CUTTING TECHNIQUE}

\begin{abstract}
Swamp corticeira is a native tree with ornamental use in urban landscape gardening with the potential to be used in unprotected and degraded areas due to its rustic feature. However, the difficulty of obtaining seeds due to its low productivity and quality, and consequent lack of uniformity in its germination makes it necessary to search for other forms of propagation of this species. Thus, this study was carried out at the Agronomy and Veterinary Medicine College of Passo Fundo University, aiming to study the formation of Erythrina crista-galli L. cuttings by applying the cutting technique. Doses of phytoregulator Indol Butyric Acid (IBA) and substrates were tested in different types of cuttings (woody plants, semi-woody plants, herbaceous and leafy plants), in four experiments. The results showed that mini-cuttings, collected from less than oneyear-old plants are the most recommended ( $75 \%$ to $100 \%$ of rooted cuttings), considering that the use of IBA decreased cutting mortality by favoring the rooting process. Due to insect attack (Isoptera) to the plants in its natural habitat, it is recommended the formation and maintenance of stock plants in the tree nursery for this cloning garden technique to provide young and healthy material in a larger scale for the propagation of this species by mini-cuttings.
\end{abstract}

Keywords: Vegetative propagation, cuttings and youthfulness.

\footnotetext{
${ }^{1}$ Recebido em 19.09.2006 e aceito para publicação em 18.12.2007.

${ }^{2}$ Programa de Pós-Graduação em Agronomia (PPG-Agro) da Faculdade de Agronomia e Medicina Veterinária (FAMV) da Universidade de Passo Fundo (UPF). E-mail : <asossella@bol.com.br>.

${ }^{3}$ PPG-Agro, FAMV, UPF, Cx. p. 611, 99.0001-970 Passo Fundo-RS. E-mail : <petry@upf.br>e <alexandre@upf.br>.
} 


\section{INTRODUÇÃO}

Pertencente à família Fabaceae, a Erythrina cristagalli L. é uma árvore que ocorre em terrenos muito úmidos, nas formações abertas secundárias, desde o Maranhão até o Rio Grande do Sul. No entanto, tolera bem ambientes drenados, o que permite incrementar o seu uso no paisagismo. O interesse pela espécie se deve ao fato de ser uma árvore nativa; às características ornamentais do caule, das folhas e das flores; ao belo arranjo espacial arquitetônico; e à alta importância ecológica, abrigando plantas epífitas e atraindo várias aves e insetos (GRATIERI-SOSSELLA, 2005). Além do valor ornamental, E. crista-galli L. é uma planta imune ao corte no Rio Grande do Sul pela Lei Estadual 9.519/92 (Art. 33º), que protege figueiras e corticeiras em todos os casos, exigindo imediata reposição da espécie em caso de corte. Embora a espécie frutifique todos os anos, as sementes são amplamente atacadas por brocas, diminuindo o potencial de regeneração natural (LORENZI, 1992; PIRES ${ }^{5}$, 2003), além do fato de o gênero apresentar sementes dormentes (LISINGEN et al., 2000), e da baixa produção de frutos em relação à de flores (NEVES et al., 2006). Apenas 6\% das flores desenvolvem sementes, em populações naturais bem conservadas (CARPANEZZI et al., 2001).

A técnica de multiplicação vegetativa mais comumente utilizada para a clonagem de plantas lenhosas, em larga escala, tem sido o enraizamento de estacas. A viabilidade da propagação comercial de mudas por estaquia depende da capacidade de enraizamento de cada espécie, da qualidade do sistema radicular formado e do desenvolvimento posterior da planta (NEVES et al., 2006). A dificuldade no enraizamento de estacas de algumas espécies pode ser superada se fornecidas condições ótimas para o enraizamento (VERGER et al., 2001). Segundo Pio et al. (2003), vários fatores podem influenciar o enraizamento das estacas, tanto intrínsecos, relacionados à própria planta, quanto extrínsecos, ligados às condições ambientais.

Verger et al. (2001) agruparam esses fatores em internos e externos. Em síntese, os fatores internos correspondem à espécie, ao clone, à idade da plantamatriz e origem, posição da estaca na planta-matriz, dimensão e estádio de desenvolvimento no momento da coleta. Os fatores externos correspondem aos tratamentos efetuados sobre a matriz, como suplementação hídrica, nutrição mineral e orgânica, condições de temperatura e luminosidade, estiolamento forçado e técnicas de manutenção ou de restauração do Estado juvenil, propício ao sucesso da propagação vegetativa. Ou, ainda, a utilização de substratos específicos, receber as estacas aportes de substâncias exógenas (auxinas,...) e estarem em ambiente com alta umidade relativa do ar (irrigação ou nebulização intermitente). Mas o sucesso de sobrevivência dessas estacas como mudas dependerá do acompanhamento agronômico (principalmente fertilização e tratamentos fitossanitários) posterior ao enraizamento.

Uma das formas mais comuns de favorecer o balanço hormonal nas estacas é a aplicação exógena de reguladores de crescimento sintéticos na base delas, elevando o teor de auxinas no tecido. A auxina sintética mais utilizada no enraizamento de estacas é o ácido indolbutírico (AIB), por se tratar de uma substância fotoestável, de ação localizada e menos sensível à degradação biológica (ASSIS e TEIXEIRA, 1998), em comparação com as demais auxinas sintéticas. Vários autores (TOFANELLI et al., 1997; RONCATO et al., 1999; BIASI et al., 2000; MARTINS et al., 2001; OLIVEIRA, 2002) relataram que o uso do AIB aumenta o número de raízes emitidas por estaca, decorrente da ação na antecipação do enraizamento, promovendo maior porcentagem de estacas enraizadas. O uso de concentrações adequadas de AIB é de extrema importância, e a dose ideal varia com a espécie (VERGER et al., 2001; HARTMANN et al., 2002). No entanto, Neves et al. (2006) relataram que o uso do AIB não incrementou a indução de raízes ou a formação de calos em estacas de Erythrina falcata Benth.

Para o controle dos fatores externos, as condições ambientais favoráveis podem ser oferecidas em ambientes protegidos, a exemplo do uso de nebulização intermitente, proporcionando umidade adequada às estacas. No caso do substrato, este desempenha importante função no processo de estaquia, basicamente por proporcionar sustentação às estacas, mantendo na sua base um ambiente úmido, escuro e suficientemente aerado (HARTMANN et al., 2002; OLIVEIRA, 2002; FERMINO e BELLÉ, 2000).

${ }^{5}$ PIRES, J. C. S. Engenheiro Agrônomo, viveirista e consultor da área ambiental. Comunicação pessoal. 
A possibilidade de utilização de espécies nativas em maior escala, tanto para fins ornamentais quanto para a vegetação de áreas desprotegidas ou degradadas, depende da disponibilidade de sementes e do conhecimento dos métodos de produção de mudas. Torna-se fundamental o estudo da formação de mudas de E. crista-galli L. pela técnica da estaquia, em função da dificuldade de obtenção de sementes, da baixa produção e qualidade destas, e da desuniformidade da germinação. Em virtude do exposto, os objetivos deste trabalho foram testar, em quatro experimentos, substratos de enraizamento e doses do fitorregulador AIB em diferentes tipos de estacas (lenhosas, semilenhosas, herbáceas e foliares) de Erythrina crista-galli L.

\section{MATERIAL E MÉTODOS}

O trabalho foi desenvolvido no Setor de Horticultura da Faculdade de Agronomia e Medicina Veterinária da Universidade de Passo Fundo, em Passo Fundo, RS, município situado na região do Planalto Médio gaúcho, norte do Estado (28 $18^{\circ}$ ' S e $52^{\circ} 24^{\prime}$ O), a $687 \mathrm{~m}$ de altitude. O clima local é descrito como subtropical úmido (Cfa), com chuvas bem distribuídas durante o ano e temperatura média anual em torno de $17^{\circ} \mathrm{C}$ (CUNHA, 1997).

A pesquisa foi conduzida em uma estufa de 210 $\mathrm{m}^{2}$, com 2,5 m de altura (pé-direito), em estrutura de alumínio galvanizado, teto em arco, revestida com polietileno de baixa densidade (PEBD), dotada de cortinas laterais móveis, instalada no sentido nordeste-sudoeste. Para a redução da temperatura e insolação (SENTELHAS e SANTOS, 1995), foi disposta internamente, a 2,5 m de altura e nas laterais, uma tela tipo "sombrite”, com capacidade para $75 \%$ de sombreamento.

O sistema de irrigação, do tipo intermitente, constou de seis linhas distanciadas em 1,5 m, com bicos nebulizadores dispostos a cada metro. O sistema, controlado por um timer, era acionado a cada $10 \mathrm{~min}$, com período de molhamento de 8 seg. Não foram obtidos dados de temperatura e umidade relativa do ar na estufa de nebulização durante a realização dos experimentos.

A espécie estudada foi Erythrina crista-galli L., conhecida como corticeira-do-banhado, sananduva, mulungu ou suinã, entre outros nomes populares, testando tipos de estacas, doses de AIB e substratos em quatro experimentos, descritos a seguir.

\subsection{Experimento 1 - Propagação da corticeira do banhado (Erythrina crista-galli L.) por estacas lenhosas no inverno e uso do AIB}

Foram testadas estacas lenhosas, coletadas em 16/06/2003, de plantas localizadas em terreno mal drenado, no Município de Passo Fundo. A planta-matriz apresentava sintomas de infestação por brocas (51\% do material coletado danificado), e a porção apical dos ramos secou, restando os ramos basais.

As estacas basais foram padronizadas com $12 \mathrm{~cm}$ de comprimento, contendo, no mínimo, dois nós, separadas em dois tipos. As estacas com diâmetro basal entre $1,5 \mathrm{~cm}$ e 2,4 cm (24,8 g de massa fresca) formaram o grupo A e aquelas de diâmetro entre 2,5 cm e 3,5 cm (54,1 g de massa fresca), o grupo B.

O experimento consistiu no tratamento desses dois grupos (A e B) de estacas com quatro doses de AIB $\left(0,1.500,3.000\right.$ e $\left.4.500 \mathrm{mg} \mathrm{L}^{-1}\right)$. O delineamento experimental utilizado foi inteiramente casualizado, com os tratamentos arranjados no sistema bifatorial ( $2 \times 4)$, com três repetições e 10 estacas por parcela (total de 240 estacas). A escolha do designe experimental foi em função do tipo de container utilizado para abrigar as estacas. Os dados foram submetidos à análise de variância (ANOVA), a comparação das médias do tipo de estacas foi pelo Teste de Tukey a 5\% de significância e a comparação de doses, pela análise de variância da regressão.

As soluções foram preparadas diluindo o AIB em $50 \mathrm{~mL}$ de álcool $93^{\circ} \mathrm{GL}$, completando o volume com água destilada até $100 \mathrm{~mL}$. Antes da imersão nas soluções de AIB, duas lesões longitudinais, em lados opostos da base das estacas, foram feitas com canivete, para provocar maior exposição do câmbio e induzir o enraizamento. A seguir, duas a duas, a base das estacas $(3 \mathrm{~cm})$ foi imersa nas soluções de AIB por $5 \mathrm{seg}$ e imediatamente enterrada cerca de $7 \mathrm{~cm}$ de profundidade no substrato de casca de arroz carbonizada. Como containers, foram utilizadas caixas plásticas de colheita de frutas, com dimensões de $59 \mathrm{~cm}$ de comprimento x $29 \mathrm{~cm}$ de largura x 12,5 cm de altura, revestidas com jornal, perfurado para permitir a drenagem.

Após 134 dias, foram avaliadas a porcentagem de estacas enraizadas e de brotadas. Paralelamente, foram colocadas em outra caixa estacas para a verificação do tempo de enraizamento, retirando, após 15 dias do início do experimento, duas estacas por semana, durante oito semanas.

R. Árvore, Viçosa-MG, v.32, n.1, p.163-171, 2008 


\subsection{Experimento 2 - Propagação da corticeira do banhado (Erythrina crista-galli L.) por estacas semilenhosas no verão e uso do AIB}

Foram testadas estacas semilenhosas, coletadas após a brotação da primavera, em 12/01/2004. As estacas, em média de $7 \mathrm{~cm}$, contendo dois nós foram subdivididas em basais, medianas e apicais .

Os tratamentos consistiram em submeter os três tipos de estacas (apicais, medianas e basais) a cinco doses de AIB (0, 1.000, 2.000, 3.000 e $4.000 \mathrm{mg} \mathrm{L}^{-1}$ ). O delineamento experimental utilizado foi em blocos casualizados, com os tratamentos arranjados num bifatorial $3 \times 5$, com quatro repetições e 10 estacas por parcela (total de 600 estacas). Os dados foram submetidos à análise de variância (ANOVA), a comparação de médias do tipo de estacas foi pelo Teste de Tukey a 5\% de significância e as doses, submetidas à análise de variância da regressão.

As estacas foram desinfestadas mediante imersão, por 5 min, em solução de hipoclorito de sódio 1\% e, posteriormente, lavadas com água corrente. Sem realizar lesão na base, as estacas foram imersas $(3 \mathrm{~cm})$, por 5 seg, nas soluções de AIB, preparadas como relatado anteriormente, e imediatamente enterradas cerca de $3 \mathrm{~cm}$ em bandejas alveoladas, contendo casca de arroz carbonizada. O material permaneceu no leito de enraizamento por 60 dias, de 12/01/2004 a 20/03/2004. Os resultados permitiram avaliar apenas a porcentagem de estacas mortas.

\subsection{Experimento 3 - Propagação da corticeira-do- banhado (Erythrina crista-galli L.) por mini- estacas herbáceas no verão e uso do AIB}

Foram utilizadas miniestacas herbáceas, retiradas de plantas com 1 ano de idade, obtidas de semente e cultivadas em vasos, contendo pelo menos duas gemas vegetativas $(4-5 \mathrm{~cm})$, com massa fresca média de 0,94 g.

Realizado concomitantemente com o experimento 2 , neste se comparou o efeito de cinco doses AIB ( 0 , 1.000, 2.000, 3.000, $4.000 \mathrm{mg} \mathrm{L}^{-1}$ ) com os tratamentos dispostos no delineamento experimental em blocos casualizados, com quatro repetições e três estacas por parcela (total de 180 estacas), considerando-se a escassez de material.

Sem realizar lesão na base, as estacas foram imersas (2 cm), por 5 seg, nas soluções de AIB e imediatamente enterradas cerca de $2 \mathrm{~cm}$ em bandejas alveoladas contendo casca de arroz carbonizada. O estudo foi conduzido por 26 dias, de 22/01/2004 a 17/02/2004.

Foram avaliadas a porcentagem de estacas enraizadas e mortas, o comprimento da maior raiz, e a massa fresca e seca da raiz e parte aérea. Os resultados foram submetidos à análise de variância da regressão.

\subsection{Experimento 4 - Propagação da corticeira-do- banhado (Erythrina crista-galli L.) por estacas foliares no verão, em diferentes substratos}

Foi testado o enraizamento de estacas foliares (folhas com pecíolos) coletadas no final do verão (primeira semana de março), oriundas de árvores que apresentavam diferentes idades cronológicas: adulta (mais de 15 anos), média (menos de 5 anos) e jovem (com 1 ano), em dois substratos: casca de arroz carbonizada (CAC) e mistura de solo mineral:CAC:composto orgânico (2:1:1), acondicionados em bandejas de isopor alveoladas.

O delineamento experimental foi em blocos casualizados, com os tratamentos arranjados num bifatorial 3 x 2, com quatro repetições e 12 estacas por parcela (total de 288 estacas). Os dados foram submetidos à análise de variância e a comparação de médias, feita pelo teste de Tukey a 5\% de significância. Após 30 dias, avaliaram-se a porcentagem de enraizamento e o comprimento da maior raiz.

\section{RESULTADOS E DISCUSSÃO}

Utilizando estacas lenhosas (Experimento 1), coletadas e colocadas para enraizar em 16/06/03, a brotação iniciouse 25 dias após e, aos 67 dias, 59,2\% das estacas se encontravam brotadas, com alguns brotos alcançando até $14 \mathrm{~cm}$ de comprimento. No entanto, a porcentagem de enraizamento foi muito baixa, de 2,5\% (três estacas) em cada tipo de estaca (grupo A - com diâmetro basal entre $1,5 \mathrm{~cm}$ e $2,4 \mathrm{~cm}$ e grupo $\mathrm{B}$ - entre $2,5 \mathrm{~cm}$ e $3,5 \mathrm{~cm}$ ).

No total de seis estacas enraizadas, quatro estacas emitiram raízes quando tratadas com a dose de 4.500 $\mathrm{mg} \mathrm{L}^{-1}$ de AIB, uma estaca com $3.000 \mathrm{mg} \mathrm{L}^{-1}$ e outra com $1.500 \mathrm{mg} \mathrm{L}^{-1}$ de AIB, indicando a tendência da necessidade de doses mais elevadas para o enraizamento da espécie, quando usadas estacas lenhosas grossas. Os resultados estão de acordo com os obtidos por Chaves et al. (2004), que, testando estacas lenhosas de Erythrina crista-galli L., obtiveram melhor resultado com $3.000 \mathrm{mg} \mathrm{L}^{-1}$ de AIB, com baixa porcentagem de 
enraizamento (8,3\%). Carpanezzi et al. (2001) afirmaram que estacas grossas dessa espécie apresentam enraizamento baixo e lento.

Embora as estacas lenhosas do Experimento 1 tivessem maior peso e, provavelmente, mais reservas nutritivas; elas foram utilizadas na intensa brotação em detrimento, provavelmente, da formação de raízes. Segundo Hartmann et al. (2002), é possível que as giberelinas causem estímulo ao crescimento vegetativo, competindo com a formação de raízes, sobre as quais tem efeito inibitório. Oliveira (2002) relatou que o enraizamento de estacas lenhosas de pessegueiro tem sido prejudicada pela brotação ocorrida, competindo com as raízes pelas reservas da estaca. Pivetta (1994) relatou, em estacas de roseiras, que as reservas utilizadas para o crescimento das raízes foram oriundas das folhas remanescentes, e a maior contribuição das folhas novas foi para o crescimento da parte aérea.

No segundo experimento, com estacas semilenhosas, coletadas e colocadas para enraizar em 12/01/04, ou seja, num período de temperaturas médias mais elevadas, que poderia auxiliar o enraizamento, o resultado foi ainda mais negativo, não ocorrendo enraizamento, com mortalidade de $100 \%$ ao final de 60 dias, demonstrando que, possivelmente, as mais elevadas temperaturas provocaram maior estresse e danos aos tecidos.

No terceiro experimento, com miniestacas herbáceas estaqueadas em 22/01/04, no mesmo ambiente e em período concomitante ao Experimento 2, a análise de regressão revelou efeito de doses de AIB apenas para mortalidade de estacas. A porcentagem de mortalidade variou de 25 a $0 \%$, e com o uso do AIB, a mortalidade foi menor, principalmente com as maiores concentrações (Figura 1). A justificativa para a menor mortalidade com o uso do AIB provavelmente seja a de que o regulador de crescimento tenha proporcionado maior rapidez no enraizamento, causando menor estresse às estacas e, conseqüentemente, maior capacidade de sobrevivência.

Em média, após 26 dias, foram obtidos 93,3\% de enraizamento. Em que pese não terem ocorrido diferenças, com a aplicação de AIB o enraizamento variou de 91,5\% a $100 \%$ e, sem o tratamento, 75\% (Tabela 1). O comprimento médio da maior raiz foi de $3,5 \mathrm{~cm}$. As massas fresca e seca das raízes foram de 0,07 g e 0,005 g e da parte aérea, de 0,94 g e 0,16 g, respectivamente (Tabela 2).

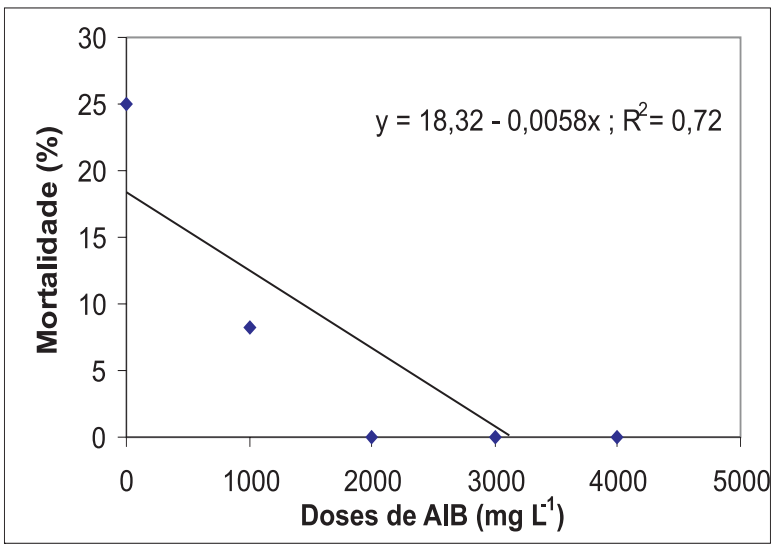

Figura 1 - Porcentagem da mortalidade de miniestacas herbáceas de corticeira do banhado (Erythrina cristagalli L.), tratadas com doses de ácido indolbutírico (AIB). Passo Fundo, RS, FAMV, 2004.

Figure 1 -Mortality percentage in herbaceous mini-cuttings of swamp corticeira (Erythrina crista-galli L.) treated with indolbutyric acid (IBA)doses. Passo Fundo, FAMV, 2004.

A massa d’água média das raízes e da parte aérea foi de 0,065 g (93\%) e 0,78 g (83\%), respectivamente. Esses valores indicam a importância do sistema de nebulização intermitente, para garantir as relações hídricas satisfatórias das estacas dessa espécie. O teor de água ficou assim compartimentado: 92,3\% na parte aérea e 7,7\% no sistema radicial.

Tabela 1 - Porcentagem de estacas enraizadas e comprimento da maior raiz de miniestacas herbáceas de corticeira do banhado (Erythrina cristagalli L.), tratadas com doses de ácido indolbutírico (AIB). Passo Fundo, RS, FAMV, 2004

Table 1 - Percentage of rooted cuttings and length of the largest root of herbaceous mini-cuttings of swamp corticeira (Erythrina crista-galli L.) treated with indolbutyric acid (IBA). Passo Fundo, RS, FAMV, 2004

\begin{tabular}{lcc}
\hline $\begin{array}{l}\text { Doses de } \\
\text { AIB }\left(\mathrm{mg} \mathrm{L}^{-1}\right)\end{array}$ & $\begin{array}{c}\text { Enraizamento } \\
(\%)\end{array}$ & $\begin{array}{c}\text { Comprimento } \\
\text { maior raiz }(\mathrm{cm})\end{array}$ \\
\hline $\mathbf{0}$ & $75,0 \pm 32,03^{\mathrm{ns}}$ & $2,7 \pm 1,51 \mathrm{~ns}$ \\
$\mathbf{1 0 0 0}$ & $91,5 \pm 17,00$ & $2,7 \pm 2,02$ \\
$\mathbf{2 0 0 0}$ & $100,0 \pm 0$ & $4,4 \pm 1,94$ \\
$\mathbf{3 0 0 0}$ & $100,0 \pm 0$ & $2,9 \pm 0,99$ \\
$\mathbf{4 0 0 0}$ & $100,0 \pm 0$ & $5,0 \pm 1,31$ \\
\hline Média & $\mathbf{9 3 , 3}$ & $\mathbf{3 , 5}$ \\
\hline C.V. (\%) & 20,4 & 48,3 \\
\hline
\end{tabular}

ns - não significativo em nível de $5 \%$;

ๆ os valores da tabela referem-se à média \pm desvio-padrão. 
Tabela 2 - Massas fresca e seca da raiz e parte aérea de mini-estacas herbáceas de corticeira do banhado (Erythrina cristagalli L.), tratadas com doses de ácido indolbutírico (AIB). Passo Fundo, FAMV, 2004

Table 2 - Fresh and dry mass of the root and shoots/leaves of the herbaceous mini-cuttings of swamp corticeira (Erythrina crista-galli L.) treated with doses of indolbutyric acid (IBA). Passo Fundo, FAMV. 2004

\begin{tabular}{|c|c|c|c|c|}
\hline \multirow[t]{2}{*}{ Doses de AIB (mg L-1) } & \multicolumn{2}{|c|}{ Massa fresca (g) } & \multicolumn{2}{|c|}{ Massa seca (g) } \\
\hline & Raiz & Aérea & Raiz & Aérea \\
\hline $\mathbf{0}$ & $0,11 \pm 0,11^{\mathrm{ns}}$ & $0,75 \pm 0,30^{\mathrm{ns}}$ & $0,000 \pm 0^{\mathrm{ns}}$ & $0,16 \pm 0,06^{\mathrm{ns}}$ \\
\hline 1000 & $0,01 \pm 0,02$ & $0,99 \pm 0,32$ & $0,000 \pm 0$ & $0,21 \pm 0,10$ \\
\hline 2000 & $0,08 \pm 0,09$ & $0,88 \pm 0,61$ & $0,005 \pm 0,01$ & $0,14 \pm 0,11$ \\
\hline 3000 & $0,04 \pm 0,04$ & $0,87 \pm 0,24$ & $0,002 \pm 0,005$ & $0,12 \pm 0,04$ \\
\hline 4000 & $0,13 \pm 0,08$ & $1,22 \pm 0,19$ & $0,008 \pm 0,005$ & $0,18 \pm 0,02$ \\
\hline Média & $\mathbf{0 , 0 7}$ & 0,94 & 0,005 & 0,16 \\
\hline C.V. (\%) & 96,7 & 38,5 & 190,0 & 48,8 \\
\hline
\end{tabular}

ns - não significativo a 5 \% pela análise de variância da regressão; I os valores da tabela referem-se à média \pm desvio-padrão.

Esses resultados, portanto, apontam para a perspectiva de se trabalhar com miniestacas, retiradas de materiais jovens, preferencialmente de jardins clonais, submetidas a tratamento com AIB, o que diminui a mortalidade das estacas.

No quarto experimento, de estacas foliares provenientes de matrizes de diferentes idades, em dois substratos, do total de 288 estacas, apenas quatro enraizaram, ou seja, $1,4 \%$. Todas eram estacas de plantas jovens (com 1 ano de idade), mantidas em substrato de casca de arroz carbonizada, apresentando comprimento da maior raiz, que variava entre 2,0 e 9,4 cm.

Os resultados obtidos nos diferentes experimentos indicaram muito baixa capacidade de enraizamento de estacas lenhosas e semilenhosas de Erythrina cristagalli, mesmo com o uso do AIB. Nas lenhosas, apenas $5 \%$ do total de estacas enraizaram (Experimento 1) e, quando utilizadas estacas semilenhosas, não houve enraizamento (Experimento 2). Estacas foliares (Experimento 4) evidenciaram potencial para o enraizamento, mas muito baixo, de apenas $1,4 \%$ do total, devendo essa técnica ser mais bem estudada. Já a estaquia de material herbáceo (miniestacas), retirado de plantas jovens, com 1 ano de idade, apresentou, após 26 dias, porcentagens de enraizamento que variaram de $75 \%$ a $100 \%$. Estacas com maior juvenilidade (menor idade fisiológica) demonstraram maior potencial de enraizamento, provavelmente por apresentarem maior concentração de auxinas endógenas, menor diferenciação e grau de lignificação, em relação àquelas provindas de plantas adultas.

Fett-Neto et al. (1998) constataram que a rizogênese é menor quanto maior a idade da planta-mãe, em espécies de Eucalyptus. Segundo Borges Junior e Martins-Corder (2002) e Paiva e Gomes (2001), a idade da planta-matriz é de fundamental importância, uma vez que, em muitas espécies arbóreas, o processo de maturidade possui correlação negativa com o potencial de formação de raízes adventícias. Hartmann et al. (2002) e Paiva e Gomes (2001) afirmaram que estacas herbáceas e semilenhosas geralmente enraízam com maior facilidade e rapidez que as lenhosas, pois a menor lignificação dos tecidos facilita a passagem das raízes formadas no periciclo.

Verger et al. (2001) ressaltaram que, entretanto, em espécies lenhosas, plantas-matriz mais velhas podem produzir estacas mais aptas a enraizar que plantas jovens, pois outros fatores podem influenciar, por exemplo, as reservas glicídicas da espécie ou clone utilizado.

Paiva e Gomes (2001) afirmaram que os problemas apresentados por materiais adultos são a produção de substâncias inibidoras do enraizamento e a lignificação, especialmente nas espécies de difícil enraizamento, que podem formar um anel de esclerênquima contínuo. Chaves et al. (2004), estudando a propagação por estacas da Erytrina crista-galli L., atribuíram a baixa porcentagem de enraizamento $(8,3 \%)$ em estacas lenhosas à grande quantidade de esclerênquima e compostos fenólicos presentes. De fato, em análise anatômica realizada no caule de E. crista-galli L. por esses autores, eles constataram a presença de grande quantidade de fibras esclerenquimáticas.

A capacidade de enraizamento, portanto, está relacionada com o conteúdo hormonal, de co-fatores, de substâncias inibidoras e de carboidratos, além das 
características do tecido vegetal, estando evidenciado na espécie estudada que os tecidos mais jovens apresentam maior potencial. Assim, algumas estratégias podem ser estudadas, como o uso de jardins clonais, podas sucessivas das matrizes para induzir a juvenilidade e o sombreamento destas.

Conforme Wendling e Xavier (2001) e Wendling et al. (2003), a implantação de jardins miniclonais, com minicepas rejuvenescidas, pode permitir a obtenção de maior vigor e qualidade dos brotos produzidos para propagação clonal por miniestaquia, principalmente em relação ao maior potencial de enraizamento, visto o maior grau de juvenilidade. O princípio do jardim clonal é recomendado por Chaves et al. (2004), para o enraizamento de estacas de Erythrina crista-galli L.

Paiva e Gomes (2001) recomendaram induzir as plantas a um estádio juvenil por meio de podas sucessivas, com o aproveitamento das brotações. Além disso, a técnica de miniestaquia, a partir de material de origem seminal, representa uma alternativa para produção de mudas de espécies florestais, principalmente nas situações em que a semente é insumo limitante (CARPANEZZI et al., 2001; WENDLING e XAVIER, 2001; XAVIER et al., 2003).

A variação no enraizamento pode ser atribuída à constituição genética dos materiais, ao estado nutricional das estacas, à sanidade e à época de colheita das estacas (ANTUNES et al., 2000). Verger et al. (2001), além de recomendarem a juvenilização de plantas-matriz para retirar as estacas, advertem que fatores climáticos naturais, como temperatura e fotoperíodo, também podem explicar efeitos de anos de maior ou menor sucesso em estaquia, o que sugere repetir os mesmos experimentos em anos subseqüentes, caracterizando a fundo o material vegetal de origem.

Conforme relataram Verger et al. (2001), é essencial definir protocolos precisos que detalhem as condições experimentais e os fatores testados, definindo critérios simples de avaliação dos resultados, porcentual e, principalmente, qualidade do enraizamento (simetria do sistema radicular), assim como o porcentual de sobrevivência após a fase do enraizamento. Dados registrados permitirão a geração de um dossiê do modo operacional de estaquia para cada espécie. Enfim, em parte é o que se buscou obter com a Erythrina cristagalli L. neste trabalho.

\section{CONCLUSÕES}

Nas condições em que os experimentos foram conduzidos, os resultados permitiram a conclusão de que:

- Estacas herbáceas de Erythrina crista-galli L. coletadas de plantas jovens, com menos de 1 ano de idade, são as mais indicadas para a propagação dessa espécie.

- O uso do AIB a partir de $1.000 \mathrm{mg} \mathrm{L}^{-1}$ pode reduzir a mortalidade e favorecer o enraizamento, quando utilizadas estacas herbáceas de plantas jovens.

- Em função do ataque de insetos (brocas) às plantas no seu habitat, recomenda-se a adoção da técnica de jardim clonal, no viveiro, fornecendo material juvenil e sadio em maior escala para a propagação dessa espécie por miniestacas.

\section{REFERÊNCIAS}

ANTUNES, L. E. C.; CHALFUN, N. N. J.; REGINA, M. A. Propagação de cultivares de amoreira-preta (Rubus spp) através de estacas lenhosas.

Revista Brasileira Fruticultura, v.22, n.2, p.195-199, 2000.

ASSIS, T. F.; TEIXEIRA,S. L. Enraizamento de plantas lenhosas. In: TORRES, A.C.;

CALDAS,L.S.; BUSO, J. A. Cultura de tecidos e transformação genética de plantas. Brasília: Embrapa-SPI/Embrapa-CNPH, 1998. v.1. 261p.

BIASI, L. A.; STOLTE, R. E.; SILVA, M. F. Estaquia de ramos semilenhosos de pessegueiro e nectarineira. Revista Brasileira

Fruticultura, v.22, n.3, p.421-425, 2000.

BORGES JUNIOR, N.; MARTINS-CORDER, M. P. Efeito do ácido indolbutírico no enraizamento de estacas de acácia negra (Acacia mearnsii De Wild.). Revista Árvore, v.26, n.2, p.223-227, 2002.

CARPANEZZI, A. A.; TAVARES, F. R.; SOUSA, V. A. Estaquia de corticeira-do-banhado (Erythrina crista-galli L.). Colombo: Embrapa Florestas, 2001. 6p.(Embrapa Florestas. Comunicado Técnico, 64).

R. Árvore, Viçosa-MG, v.32, n.1, p.163-171, 2008 
CHAVES, M. C. R. et al. Enraizamento e morfo-anatomia de estacas caulinares de Erythrina cristagalli L. (Fabaceae).

Disponível em: <http://www.adaltech.com.br/ evento/museugoeldi/resumoshtm/resumos/ R0334-1.htm> Acesso em: 25 maio 2004.

CUNHA, G. R. Meteorologia: fatos \& mitos. Passo Fundo: Embrapa - CNPT, 1997. 268p.

FERMINO, M. H.; BELLÉ, S. Substratos hortícolas. In: PETRY, C. (ORG.) Plantas ornamentais: aspectos para produção. Passo Fundo: Universidade de Passo Fundo, 2000. p.29-40.

FETT-NETO, A. G.; FETT, J. P.; FERREIRA, A. G. Papel de auxina exógena e luz no enraizamento adventício de Eucalyptus saligna e Eucalyptus globulus. In: CONGRESSO NACIONAL DE BOTANICA, 49., 1998, Salvador. Resumos... São Paulo/Porto Alegre: IB/UFRGS, 1998. p.166.

\section{GRATIERI-SOSSELlA, A. Potencialidade} ornamental e paisagística, caracterização morfo-anatômica e propagação de Erythrina crista-galli $L$. 2005. 162f. Dissertação (Mestrado em Agronomia/ Produção Vegetal) - Universidade de Passo Fundo, Passo Fundo, 2005.

HARTMANN, H. T. et al. Hartmann and Kester's plant propagation: principles and practices. 7.ed. New Jersey: Prentice Hall, 2002. 880p.

LISINGEN, L. Von et al. Propagação vegetativa de Erythrina speciosa (Andrews) através do uso de fitorreguladores. In: CONGRESSO NACIONAL DE BOTANICA, 51., 2000, Brasília. Resumos... Brasília: Universidade de Brasília, 2000. p.45.

LORENZI, H. Árvores brasileiras. São Paulo: Plantarum, 1992. 203p.

MARTINS, A. B. G.; GRACIANO, F. A.; SILVA, A. V. C. Clonagem do Jambeiro-rosa (Syzygium malacensis) por estaquia de ramos enfolhados.

Revista Brasileira de Fruticultura, v.23, n.2, p.365-368, 2001.

R. Árvore, Viçosa-MG, v.32, n.1, p.163-171, 2008
NEVES, T. S. et al. Enraizamento de corticeira-daserra em função do tipo de estaca e variações sazonais. Pesquisa Agropecuária Brasileira, v.41, n.12, p.1699-1705, 2006.

OLIVEIRA, A. P. Uso de ácido indolbutirico no enraizamento de estacas semilenhosas e lenhosas de pessegueiro. 2002. 96f. Dissertação (Mestrado em Agronomia / Produção Vegetal) - Universidade de Passo Fundo, Passo Fundo, 2002.

PAIVA, H. N.; GOMES, J. M. Propagação vegetativa de espécies florestais. Viçosa, MG: Universidade Federal de Viçosa, 2001. (Série Cadernos Didáticos, 83)

PIO, R. et al. Enraizamento de estacas apicais de figueira tratadas com sacarose e ácido indolbutírico por imersão rápida. Revista Brasileira Agrociência, v.9, n.1, p.35-38, 2003.

PIVETTA, K. F. L. Estudos sobre enraizamento de estacas enfolhadas de roseira (Rosa sp.) “Red succes”. 1994. 151f. Dissertação (Mestrado em Agronomia / Produção Vegetal) - Universidade Estadual Paulista, Jaboticabal, 1994.

RONCATO, G. et al. Influência do sombreamento das plantas e do ácido indolbutírico no enraizamento de estacas de laranjeira (Citrus sinensis (L.) Osbeck) cv. Valencia. Revista Científica Rural, v.4, n.2, p.60-65, 1999.

SENTELHAS, P. C.; SANTOS, A. O. Cultivo protegido: aspectos microclimáticos. Revista Brasileira Horticultura Ornamental, v.1, n.2, p.108-115, 1995.

TOFANELLI, M. B. D. et al. Enraizamento de estacas lenhosas e semilenhosas de cultivares copa de pessegueiro em diferentes concentrações de ácido indolbutírico. Revista Brasileira de Fruticultura, v.19, n.2, p.259-263, 1997.

VERGER, M. et al. Bouturage horticole des ligneux. Revue Horticole PHM, n.431, p.27-29, 2001.

WENDLING, I.; XAVIER, A. Gradiente de maturação e rejuvenescimento aplicado em espécies florestais. Floresta Ambiente, v.8, n.1, p.187-194, 2001. 
WENDLING, I.; XAVIER, A.; PAIVA, H. N.

Influência da miniestaquia seriada no vigor de minicepas de clones de Eucalyptus grandis.

Revista Árvore, v.27, n.5, p.611-618, 2003.
XAVIER, A.; SANTOS, G. A.; OLIVEIRA, M. L.

Enraizamento de miniestaca caulinar e foliar na propagação vegetativa de cedro-rosa (Cedrela fissilis Vell.). Revista Árvore, v.27, n.3, p.139-143, 2003. 